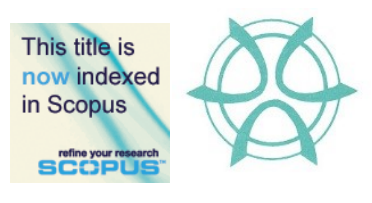

PLANNING MALAYSIA:

Journal of the Malaysian Institute of Planners

VOLUME 19 ISSUE 3 (2021), Page 13 - 22

\title{
EXPLORING THE USAGE OF DIGITAL TECHNOLOGIES FOR CONSTRUCTION PROJECT MANAGEMENT
}

\author{
Tung, Yew-Hou ${ }^{1}$, Chia, Fah-Choy ${ }^{2}$, Felicia Yong, Yan-Yan ${ }^{3}$ \\ Lee Kong Chian Faculty of Engineering and Science \\ UNIVERSITI TUNKU ABDUL RAHMAN, MALAYSIA
}

\begin{abstract}
Digital technologies have recently started to enter the construction industry, gradually changing how infrastructure, real estate and other built assets are designed, constructed, operated and maintained. Being among the least digitalized sectors, it is predicted that digital technologies will substantially increase the productivity, decrease the costs, and improve site safety of construction projects. Thus, the primary objective of this pilot study is to explore the usage of digital technologies for the 12 components of construction project management. A total of 32 respondents participated in the online survey. The results indicate that the usage of digital technologies was significantly higher in the management of scheduling, documenting, designing, and assigning costs. The aspects for digitalized safety, stakeholders, equipment, and materials are room for further improvement.
\end{abstract}

Keywords: Digital Technologies, Construction Industry, Project Management

\footnotetext{
${ }^{1}$ Student at University Tunku Abdul Rahman. Email: tungyh@utar.edu.my
} 
Tung Yew-Hou, Chia Fah-Choy, Felicia Yong Yan-Yan

Exploring the Usage of Digital Technologies for Construction Project Management

\section{INTRODUCTION}

The construction industry is triggered by the world's megatrends such as the growing population, or the increasing demand for infrastructure and housing projects. The construction industry intends to improve the image of remarkably poor productivity by pursuing the Fourth Industrial Revolution (4IR), which involves the integration of digital technologies into all existing business areas. The digital transformation in the construction industry involves the introduction of Industrialised Building Systems (IBSs), Building Information Modelling (BIM), Augmented Reality (AR) and Virtual Reality (VR), and Unmanned Aerial Vehicles (UAVs), and has given a different elucidation of built environment to the public (Abdullah, Rashid, Tahar \& Osoman, 2021; Ramu, Taib \& Aziz, 2020; Chai, 2017).

Digitalisation has raised the production of the construction industry. IBSs manufacture distinct components and are ready to erect modular units off site. BIM is no longer restricted to dimensional modelling. Nevertheless, the BIM model can be shown in different platforms that can be consolidated with various digital devices. AR and VR are initially only beneficial for game design, but the idea was executed for training purposes in the built environment. Digitalisation will change nearly everything that allows the industry to improve to the newest, recognised innovative methods (Chai, 2017).

The Malaysian construction industry is advancing, although at a laggy pace. The idea of digitalisation has been highly acknowledged in the country. The Malaysian construction industry is in a transformation stage, changing from analog to digital. The preparedness of the stakeholders in connection with business model, finance, planning, operation, and maintenance of organization, together with the top management's commitment, are improving digitalisation. Nevertheless, the digital age progresses quickly, and the industry either accepts the megatrend to advance forward, or risks being left behind (Chai, 2017).

\section{LITERATURE REVIEW}

\section{Digital Technologies: Barriers in Construction Project Management}

The current practice of the construction industry makes digital evolution remarkably difficult. Construction companies find it even harder to develop digital solutions that can be applied to multiple projects. Often, the individual departments of a company will develop their own digital solutions, without coordinating with others (Koeleman, Ribeirinho, Rockhill, Sjodin \& Strude, 2019).

Construction projects are usually fragmented throughout a project life cycle. The specialists of consultants normally operate in a small number of disciplines. Each stage of the project life cycle involves a different group of contractors and subcontractors. Therefore, it is extremely hard to develop digital 
solutions across a construction project that requires coordinating changes among project stakeholders (Koeleman et al., 2019).

Construction projects have distinctive requirements that involve bespoke design and delivery approaches. These approaches are hardly repeated; therefore, it is difficult to initiate changes across several projects, because it involves thorough transformation. (Koeleman et al., 2019).

Typically, a new construction project engages a new arrangement of organizations working together. Project stakeholders are hardly regular. Contractors will have similar encounters at the company level, where workforce turnover is high. Instability at the project and company levels makes it difficult for construction companies and the involved parties to establish new working approaches and competencies that seamlessly transfer from one project to the next (Koeleman et al., 2019).

The large scale of construction companies is likely to be associated with departments adhering to their own procedures in preference to specific standards, especially since many have expanded by obtaining small-scale companies where project sites located far away from the company's headquarters. It is encouraging for supervising workers to implement new working approaches or use advanced technologies (Koeleman et al., 2019).

\section{Digital Technologies: Trends in Construction Project Management}

Experts foresee that construction programmes will be reduced persistently, as clients expect more efficiency in project delivery. Also, the shortage of skilled labour and raw materials will increasingly challenge those involved in construction projects. Therefore, construction companies are expected to integrate digital technologies into their processes in order to retain their competitive edge (Smartsheet, 2018).

Construction projects usually involve several phases before completion. It is normal to have changes due to project constraints, especially when waiting for information or an approval for implementation. As the changes may affect the scope of the project, the updated information must be instantly accessed by all the affected parties through digital devices and platforms. With real-time updating, project delivery performance and transparency will be improved as project managers will be able to know actual happenings at site, to monitor and make timely decisions if there are any site issues (Smartsheet, 2018).

Site safety is highly important for any construction project. Due to busy workload, workers may be reluctant or forget to report any spotted site safety issues. To reduce accident rates, contractors should make it convenient for workers to report safety issues by using their mobile phones to scan the QR codes on the on site safety signs. Alternatively, workers can take pictures attached to an online form as well. Once the issues are reported, the relevant parties, namely, site officers and construction managers, must conduct immediate inspection and 
Tung Yew-Hou, Chia Fah-Choy, Felicia Yong Yan-Yan

Exploring the Usage of Digital Technologies for Construction Project Management

resolve them without any delay, to create a highly safer work environment (Smartsheet, 2018).

All project parties, regardless of whether they are based on site or at the head office, can access real-time and comprehensive project information if allowed by the company. There are many project documents such as contracts, documents, drawings, specifications, progress reports, requests for information, testing logs, inspection logs, master programmes, financial statements, progress claims, and interim certificates that make documentation easy for the project parties to access when needed by using cloud-based technology (Smartsheet, 2018).

There are many types of project deliverables in construction projects. It is crucial to access and share the status of work done in real-time by using cloudbased technology. All project parties are responsible for their outstanding work, as the other parties can view the status of each item and who is accountable for it. Many project documents require approval or sign-off before the work can be executed in construction projects. However, it is hard to obtain all the key project stakeholders to sit down and get the instructions signed by everyone physically. This can be overcome and expedited by collecting electronic signatures through circulation of the project documents (Smartsheet, 2018).

The shortage of skilled and knowledgeable workers is a common and long-standing issue in the construction industry. But this would not be a reason for construction companies to deliver a project with a longer lead time. Conversely, the contractor especially must retain the same speed and efficiency with a compact workforce, due to the competition getting increasingly fierce in the industry. To sustain the construction business, automating repetitive tasks by adopting reliable software is an option. For instance, BIM software would benefit construction companies by coordinating trades and subcontractors, detecting any clashes before construction begins, visualizing the entire project during preconstruction, and improving onsite collaboration and communication (Hall, 2018).

\section{RESEARCH METHODOLOGY}

\section{Sampling Design and Research Procedure}

This research was based on a pilot survey conducted using an online questionnaire. It was achieved through the following processes:

1) Sample Definition. This pilot study aims to explore the usage of digital technologies in construction-related companies. Therefore, the target respondents included the following construction practitioners: consultancy, construction businesses, property developments, construction materials, manufacturer and merchants, and other related parties with certain working experience in the industry and working in established construction-related companies that involve different types of construction projects such as 
commercial, industrial, infrastructure, residential, renovation or refurbishment.

2) Questionnaire Validation. In validating a survey, face validity was established. First, experts who understand the topic read through the questionnaire to ensure the questions effectively capture the topic under investigation. Second an expert in construction checked the survey for common errors like double-barrelled, confusing, or leading questions.

3) Questionnaire Design. The questionnaire was created by using Google Forms. Google Forms provides a fast way to create an online survey. Once the online questionnaire is created, an invitation was sent out by the researcher to potential respondents for participation through email. The survey instrument was divided into two sections. Section A consists of questions about general responses on the usage of digital technologies when managing different components of construction projects, while Section B comprises questions concerning respondents' demographic information.

4) Data collection. Data was collected from February to July 2019. The duration was about six months.

5) Data analysis. Analysis of the data started in the month of August 2019. The Statistical Package for the Social Sciences (SPSS) software was used to check and analyze the data.

\section{RESULTS AND DISCUSSION}

The online questionnaire was sent out to construction practitioners through email. Only 32 respondents out of approximately 250 construction practitioners (or $12.8 \%$ ) answered the online questionnaire. Fryrear (2020) mentioned that external surveys will generally receive a $10 \%-15 \%$ response rate on average, and Hill (1998) suggested that 10-30 respondents for pilots in survey research will be sufficient for reporting the findings of a study. Table 1 summaries the respondents' demographics.

Table 1: Respondents' Demographics

\begin{tabular}{|c|c|c|}
\hline Descriptions & Number of Respondents & Percentage \\
\hline \multicolumn{3}{|l|}{ Nature of business } \\
\hline Consultancy & 10 & 31.3 \\
\hline Construction business & 9 & 28.1 \\
\hline Property development & 11 & 34.4 \\
\hline Building materials manufacturer & 1 & 3.1 \\
\hline Building materials merchants & 1 & 3.1 \\
\hline Others & 0 & 0.0 \\
\hline \multicolumn{3}{|l|}{ Working experience in construction } \\
\hline industry & 10 & 31.3 \\
\hline Less than 2 years & 6 & 18.8 \\
\hline $2-5$ years & 4 & 12.5 \\
\hline & 17 & (C) 2021 by MII \\
\hline
\end{tabular}


Tung Yew-Hou, Chia Fah-Choy, Felicia Yong Yan-Yan

Exploring the Usage of Digital Technologies for Construction Project Management

$6-10$ years 7

$1-20$ years 5

21.9

More than 20 years

15.6

Number of company employees

Less than 5

12.5

$5-29$

40.6

$30-75$

$\begin{array}{rr}13 & 40.6 \\ 6 & 18.8\end{array}$

More than 75

28.1

Types of construction project

Commercial

Industrial

Infrastructure

Residential

Renovation or refurbishment works

The Cronbach Alpha's test was used to measure the reliability of the internal consistency of the scale. Next, the internal consistency links to the interrelatedness of the item in a test by describing the same concept or structure. There is no lower limit to the coefficient of the Cronbach's Alpha value. The Cronbach's Alpha reliability coefficient normally varies between 0 and 1 . The closer the coefficient is to 1.0 , the more the internal consistency of the items in the rating scale. Moreover, the reliability of the test allows the researcher to reveal the amount of measurement error within the test (Tavakol and Dennick, 2011). The Cronbach's Alpha for the usage of digital technologies for construction projects management components was 0.948 . The value indicated high reliability of internal consistency. Concisely, the variables were reliable, since all of Cronbach's Alpha values were over 0.700.

Statistical tests require that the data are normally distributed. Therefore, checking is always required if this assumption is violated. In this case, the null hypothesis is that the data is normally distributed, and the alternative hypothesis is that the data is not normally distributed. Two tests that are used for normality. For a dataset smaller than 2,000 elements, the Shapiro-Wilk test is used; otherwise, the Kolmogorov-Smirnov test should be used (MST, 2020). For this case, since it only has 384 elements in total, the Shapiro-Wilk test was employed. According to Table 2 , most of the p-values were less than 0.050 , and the null hypothesis was rejected. Hence, we conclude that this dataset did not come from a normal distribution 
PLANNING MALAYSIA

Journal of the Malaysia Institute of Planners (2021)

Table 2: Tests of Normality

\begin{tabular}{l|c|c}
\hline \multirow{2}{*}{ Construction Projects Management Components } & \multicolumn{2}{|c}{ Shapiro-Wilk } \\
\cline { 2 - 3 } & Statistic & Sig. \\
\hline Contract & .937 & .061 \\
Cost & .926 & .031 \\
Design & .904 & .008 \\
Document & .937 & .060 \\
Equipment & .861 & .001 \\
Materials & .876 & .002 \\
Performance & .935 & .053 \\
Productivity & .928 & .034 \\
Quality & .912 & .013 \\
Safety & .874 & .001 \\
Schedule & .893 & .004 \\
Stakeholder & .923 & .026 \\
\hline
\end{tabular}

The Friedman test is the nonparametric equivalent of a one-sample repeated measures design or a two-way analysis of variance with one observation per cell. Friedman tests the null hypothesis that $\mathrm{k}$ related variables come from the same population. For each case, the $\mathrm{k}$ variables are ranked from 1 to $\mathrm{k}$. The test statistic is based on these ranks (Laerd, 2020). Table 3 shows the mean rank for each of the related groups. The Friedman test compares the mean ranks between the related groups, and indicates how the groups differ. It was included for this reason. Table 4 provides the test statistic (x2) value ("Chi-square"), degrees of freedom (df), and the significance level ("Asymp. Sig."), which are all required to report the results of the Friedman test. In this study, there was a statistically significant difference in digital technologies usage for construction project management components $(\mathrm{p}=0.00,<0.05)$. It is important to note that the Friedman test is an omnibus test to investigate whether there are overall differences, but does not pinpoint which groups in particular differ from each other (Laerd, 2020).

In the context of the Malaysian construction industry, there were higher digitalized practices for the management of schedule, document, design and cost, such as rescheduling works in real-time, alerting teams on critical items, key milestones through mobile platforms, submitting and processing Request for Information (RFI) in real-time, sharing site information, visualising construction drawings , updating and distributing drawings, designing information, and updating and tracking and changing log status, all done on mobile platforms. However, practices for safety, stakeholder, equipment, and materials were less digitalized, such as tracking and reporting safety incidents, alerting workers on 
Tung Yew-Hou, Chia Fah-Choy, Felicia Yong Yan-Yan

Exploring the Usage of Digital Technologies for Construction Project Management

safety precautions, updating stakeholders' details, deploying and tracking construction equipment and machinery, identifying, tracking and locating materials, and updating materials wastage and excess, all mostly done on mobile platforms.

Table 3: Ranks

\begin{tabular}{lc}
\hline Construction Projects Management Components & Mean Rank \\
\hline Schedule & 9.38 \\
Document & 8.59 \\
Design & 8.20 \\
Cost & 7.61 \\
Productivity & 6.50 \\
Performance & 6.39 \\
Contract & 5.88 \\
Quality & 5.67 \\
Materials & 5.22 \\
Equipment & 4.89 \\
Stakeholder & 4.86 \\
Safety & 4.81 \\
\hline
\end{tabular}

\begin{tabular}{lr}
\multicolumn{2}{c}{ Table 4: Test Statistics } \\
\hline $\mathrm{N}$ & 32 \\
Chi-Square & 87.516 \\
$\mathrm{df}$ & 11 \\
Asymp. Sig. & .000 \\
\hline
\end{tabular}

The results indicate that digital technologies were not commonly adopted in the construction stages in the Malaysian construction industry. It further shows that the industry is yet to catch up with digital transformation. This phenomenon may relate to the characteristics of the construction industry and the lack of commitment from top management and key stakeholders. To improve the performance of construction projects, construction companies should be committed to invest more in digital technologies. Also, the companies need to change the fundamental aspects of their structure, culture and information technology systems for seamless integration.

\section{CONCLUSION}

The construction industry is among the least digitalized industries that suffer from poor organization and productivity, complicated requirements, low profit margins, inadequate communication, and limited talent development. This situation should not be allowed to continue, as all the problems are critical, and 
population growth, urbanisation and economic expansion are predicted to increase global demand for construction output by $85 \%$ by 2030 (Atom \& CIOB, 2019). Therefore, the construction industry must embrace digital technologies and adopt new approaches to manage and deliver the projects for better success. This study has indicated that there was a statistically significant difference in digital technologies usage for construction project management components in the context of the Malaysian construction industry. The results show there were higher digitalized practices for the management of schedule, document, design and cost. However, practices for safety, stakeholder, equipment, and materials were less digitalized. Thus, it is recommended that construction players invest in more resources to enhance the digital technologies in a more holistic way, in order to enhance construction project delivery.

\section{REFERENCES}

Atom \& CIOB. (2019). Reimagining construction: transformed by technology. Retrieved from: https://www.constructionmanagermagazine.com/cpd-articles/reimaginingconstruction-transformed-technology/

Abdullah, S., Rashid, M. F. A., Tahar, K. N., \& Osoman, M. A. (2021). Tree Crown Mapping based on unmanned aerial vehicle (UAV) towards a green-sustainable residential. Planning Malaysia Journal of the Malaysian Institute of Planners, 19(2), 97-107.

Chai, C.S. (2017). Digitalisation in built environment. Retrieved from: https://ipm.my/digitalisation-built-environment/

Fryrear, A. (2020). What's a good survey response rate? Retrieved from: https://www.surveygizmo.com/resources/blog/survey-response-rates/

Hall, J. (2018). Top 10 benefits of BIM in construction. Retrieved from: https://bim360resources.autodesk.com/connect-construct/top-10-benefits-of-bimin-construction

Hill, R. (1998). What sample size is "enough" in internet survey research. Interpersonal Computing and Technology: An electronic journal for the 21st century, 6(3-4), 112.

Koeleman, J., Ribeirinho, M.J., Rockhill, D., Sjodin, E. \& Strude, G. (2019). Decoding digital transformation in construction. Retrieved from: https://www.mckinsey.com/industries/capital-projects-and-infrastructure/ourinsights/decoding-digital-transformation-in-construction

Laerd. (2020). Friedman test in SPSS statistics. Retrieved from: https://statistics.laerd.com/spss-tutorials/friedman-test-using-spss-statistics.php

MST. (2020). Performing normality in PASW (SPSS). Retrieved from: http://www.maths-statistics-tutor.com/normality_test_pasw_spss.php

Ramu, V., Taib, N., \& Aziz, N. F. (2020). The attributes of future social learning built environments towards 21 st century education in tertiary education. Planning Malaysia Journal of the Malaysian Institute of Planners, 18(3), 326-337.

Smartsheet. (2018). A digital transformation report: five emerging trends in the $\begin{array}{lll}\text { construction } & \text { industry. } & \text { Retrieved }\end{array}$ 
Tung Yew-Hou, Chia Fah-Choy, Felicia Yong Yan-Yan

Exploring the Usage of Digital Technologies for Construction Project Management

https:/www.smartsheet.com/sites/default/files/13619-Report-Construction-

DIGITAL.pdf

Tavakol, M., \& Dennick, R. (2011). Making sense of Cronbach's alpha. International journal of medical education, 2, 53.

Received: $12^{\text {th }}$ July 2021. Accepted: $23^{\text {rd }}$ Sept 2021 